\title{
Estimation of Soil Respiration by Its Driving Factors Based on Multi-Source Data in a Sub-Alpine Meadow in North China
}

\author{
Yanan Liang ${ }^{1,2,4}$, Yanpeng Cai ${ }^{1,3,4, *}$, Junxia Yan ${ }^{2, *}$ and Hongjian $\mathrm{Li}^{2}$ \\ 1 State Key Laboratory of Water Environment Simulation, School of Environment, Beijing Normal University, \\ Beijing 100875, China; 201831180022@mail.bnu.edu.cn \\ 2 Institute of Loess Plateau, Shanxi University, Taiyuan 030006, China; hongli@sxu.edu.cn \\ 3 Institute for Energy, Environment and Sustainable Communities, University of Regina, 120, 2 Research Drive, \\ Regina, SK S4S 7H9, Canada \\ 4 Beijing Engineering Research Center for Watershed Environmental Restoration \& Integrated Ecological \\ Regulation, School of Environment, Beijing Normal University, Beijing 100875, China \\ * Correspondence: yanpeng.cai@bnu.edu.cn (Y.C.); yjx422@sxu.edu.cn (J.Y.)
}

Received: 2 May 2019; Accepted: 1 June 2019; Published: 13 June 2019

\begin{abstract}
Soil respiration $\left(R_{\mathrm{S}}\right)$ in high-altitude areas are normally sensitive to varying climatic conditions. The objective of this research was mainly to explore temporal variations in $R_{\mathrm{S}}$ rates and the corresponding controlling factors for the establishment of appropriate fitting models in a sub-alpine meadow of north China. The data was obtained through field measuring and extraction of the Moderate Resolution Imaging Spectroradiometer (MODIS) in the geographical unit of the study site over the period of 2007 to 2015 . The main results were as follows: (1) seasonal variations in $R_{\mathrm{s}}$ rates, soil temperature $\left(T_{\mathrm{S}}\right)$, land surface temperature (LST), and normalized difference vegetation index (NDVI) all produced symmetrical bell type patterns, while soil moisture $\left(M_{\mathrm{S}}\right)$ showed a fluctuating pattern, (2) a $T_{\mathrm{s}}$-exponential model could greatly capture seasonal variations of $R_{\mathrm{s}}$ rates in the study site, reflecting the role of temperature as a dominant driving factor in determining $R_{\mathrm{s}}$ temporal variations in alpine meadow areas, (3) there was no significant difference between the performing indicators evaluating the proposed $T_{\mathrm{S}}$-exponential model and the LST-exponential model. This indicated great potential for applying remote sensing products to estimate seasonal $R_{\mathrm{S}}$ rates and 4) seasonal variations in $R_{\mathrm{S}}$ rates towards temperature sensitivity $\left(\mathrm{Q}_{10}\right)$ showed a concave curve and dramatically decreased as the temperature increased from -1 to $11^{\circ} \mathrm{C}$. Overall, the results indicated that attention to significant effects of climatic conditions on $R_{\mathrm{s}}$, particularly in areas of low temperature, should be warranted. Also, applicability of remote sensing products for estimating $R_{\mathrm{s}}$ was reflected and demonstrated.
\end{abstract}

Keywords: Soil respiration; seasonal variations; spatial data products; model specification; $\mathrm{Q}_{10}$ values; sub-alpine meadow

\section{Introduction}

In the past decades, concerns over the global carbon cycle are increasingly high due to its close relationships with global warming [1,2]. Increasing concentration of $\mathrm{CO}_{2}$ in the atmosphere is believed as the primary factor for the generation of greenhouse effects [3]. Moreover, the exchange of $\mathrm{CO}_{2}$ between the atmosphere and soil results in certain feedback to climatic change [4].

Soil $\mathrm{CO}_{2}$ efflux, hereafter referred to as soil respiration $\left(R_{\mathrm{s}}\right)$, is the second largest terrestrial carbon efflux and therefore considered to be one of the most significant components of the global carbon balance [5]. Raich and Potter [6] estimated that about 50-77 $\mathrm{Pg} \mathrm{C} \mathrm{yr}^{-1}$ of $\mathrm{CO}_{2}$ was released from the 
soil to the atmosphere, accounting for approximately $60 \%-90 \%$ of the ecosystem respiration, $40 \%-60 \%$ of the total primary productivity [7], and almost 10 times the amount of $\mathrm{CO}_{2}$ emitted by industrial combustion (5 $\left.\mathrm{Pg} \mathrm{C} \mathrm{yr}^{-1}\right)[8,9]$. Moreover, the value of the "missing carbon sink" has increased, making it essential to study the response of $R_{\mathrm{s}}$ to climatic change. Additionally, quantitative observation of $R_{\mathrm{S}}$ is crucial to accurately estimating the carbon budget of a given area $[2,10]$.

Soil respiration is a complex process of $\mathrm{CO}_{2}$ emission that involves autotrophic respiration and heterotrophic respiration, including the production of $\mathrm{CO}_{2}$ by plant roots, soil microbes, and soil fauna, and the subsequent emission of $\mathrm{CO}_{2}$ from soil to the atmosphere [11,12]. Thus, $R_{\mathrm{s}}$ is affected by a combination of environmental factors including temperature [13], soil water content [14], rainfall events $[15,16]$, photosynthetic rate, physical and chemical characteristics of soil such as the dissolution of carbonates due to acidification in calcareous and limed acidic soils [11,17], soil biological properties [18], solar radiation, landform factors [3], and external disturbances [10]. Therefore, these biotic and abiotic elements could potentially provide effective parameter inputs for the modeling of $R_{\mathrm{s}}$. Predicted dynamic models of $R_{\mathrm{S}}$ variation based on all related environmental factors affecting $R_{\mathrm{S}}$ are complex and often constructed according to several key factors controlling the main process. There is considerable evidence suggesting that $R_{\mathrm{S}}$ is closely related to variations in temperature in most ecological scenarios [5,19], as well as to the soil moisture in dry conditions [20], and gross primary photosynthesis (GPP) or vegetation indexes [21] in ecosystems with high coverage. Although the effects of these factors on $R_{\mathrm{S}}$ could not be separated directly, the relative significance of each variable to $R_{\mathrm{S}}$ differs in various ecosystems. The temperature sensitivity index of $R_{\mathrm{S}}\left(\mathrm{Q}_{10}\right)$ has often been used to describe the dependence of $R_{\mathrm{S}}$ on temperature; however, it is actually not constant at temporal or spatial scales. Rather, its value varies under different temperature conditions [2], especially at lower temperatures. Understanding the variation characteristics of $Q_{10}$ is a key step in investigation of $R_{\mathrm{S}}$ characteristics that contributes to the rational estimation of regional carbon budgets.

An infrared gas dynamic analysis system is a reliable and convenient field soil carbon dioxide flux observation method within higher measuring accuracy than that of the static method. However, the observed results can only represent the carbon flux characteristics of a specific ecosystem in the particular environment, and it can not be directly applied to other regions. Also, long-time series quantification of $R_{\mathrm{s}}$ measured in situ remains challenging because of the need to conduct great amounts of field work and the uncertainties regarding different ecological scenarios. Increasing the sample size under the background of global climatic change is critical to accurately investigating the dynamic balance of the carbon cycle. Remote sensing is the only feasible means for large-scale continuous and quantitative observation of ecological indicators at present. It is a low-cost and convenient method of acquiring land surface parameters indirectly, which compound the mixed effects of plants and soil. This technique has been proven to be valid for the estimation of surface parameters (land surface temperature, soil water content, and surface reflectivity), but is less applicable to underground biochemical processes such as $R_{\mathrm{S}}$ [22,23]. Some researchers have recently used more accessible land surface parameters to build spatial [5] or temporal variation models of $R_{\mathrm{S}}$ to predict $R_{\mathrm{S}}$ based on empirical models and provide data supporting the carbon budget on a large scale. The application of remote sensing to studies of $R_{\mathrm{S}}$ based on long-term observations is not easy and has seldom been conducted. Therefore, taking the combination of remote sensing technology and ecology process as the breakthrough point and integrating multi-source data containing in situ measured data and spatial data products to study soil respiration along long time series is not only the demand for the development of remote sensing application, but also an effective way to solve the scale expansion of field observing.

As the second largest geographic unit in China, accounting for $70 \%$ of the world's loess distribution and the largest loess accumulation area in the world, the Loess Plateau region has formed its own unique climate and topography, within the characteristics of high altitude distribution, is also faced with a lot of ecological function decline such as soil erosion, vegetation destruction caused by human 
activities, and climatic change. The terrestrial carbon cycle in the Loess Plateau is an important component of the global carbon balance.

Sub-alpine meadows are widely distributed in China, which are dominated by perennial herbs. As an important type of grassland ecosystem, ecological investigations of sub-alpine meadows have received the attention of researchers because their ecological functions are far greater than their economic values. In the present study, a typical mountain meadow in the Loess Plateau, which was one of only four meadows in Shanxi province, was investigated. The carbon balance in this high-altitude distributed ecosystem is extremely sensitive to climatic change; therefore, the temporal characteristics of the carbon cycle were investigated to provide basic datasets with actual reference values. Furthermore, applying Moderate Resolution Imaging Spectroradiometer (MODIS) data to the temporal variation model of in situ measured $R_{\mathrm{S}}$ will verify the science significance and feasibility of estimating $R_{\mathrm{S}}$ using remote sensing data.

The study was conducted to explore the temporal dynamics in $R_{\mathrm{s}}$ as well as its connections to temperature, soil moisture and vegetation index in a sub-alpine meadow in north China based on field measuring data and spatial data products. Thereafter the dynamic response model of seasonal variations in $R_{\mathrm{S}}$ could be formulated by its driving primary factors based on multi-source data, further quantitively examining the dominant role of temperature in soil respiration in the sub-alpine meadow zone and the potential applicability of spatial data products to estimate $R_{\mathrm{s}}$. The hypotheses of this study were: (1) seasonal variations in $R_{\mathrm{S}}$ would be effectively estimated by its primary driving factors, (2) $R_{\mathrm{S}}$ was most sensitive to temperature variations in study area thus temperature would act as a key role in estimating seasonal variations in $R_{\mathrm{s}}$ in the sub-alpine meadow zone, and (3) MODIS products would be reliable indicators for the quantitative estimation of $R_{\mathrm{s}}$ in a certain statistical sense.

\section{Materials and Methods}

\subsection{Overview of the Studying Site}

A long-term study was conducted in Pangquangou National Natural Reserve $\left(37^{\circ} 47^{\prime} 45^{\prime \prime}-37^{\circ} 55^{\prime} 50^{\prime \prime} \mathrm{N}\right.$, $111^{\circ} 22^{\prime} 33^{\prime \prime}-111^{\circ} 32^{\prime} 22^{\prime \prime}$ E; $10,443 \mathrm{hm}^{2}$ ) (Figure 1) in Shanxi Province, which is a rare green field on the Loess Plateau. The study area is located in the warm temperate continental monsoon climate zone, which is characterized by a cool and rainy summer and autumn and a cold, dry winter. A typical mountain climate has formed in the area because of the influence of the altitude and topography. According to the meteorological station, the average annual temperature is $3^{\circ} \mathrm{C}-4{ }^{\circ} \mathrm{C}$, with a monthly average temperature of $16.1^{\circ} \mathrm{C}$ in July and $-10.6{ }^{\circ} \mathrm{C}$ in January. The annual sunshine duration in the region is $2500-2800 \mathrm{~h}$ and the active accumulated temperature $\left(\geq 10^{\circ} \mathrm{C}\right)$ was $2100^{\circ} \mathrm{C}$. In addition, the annual precipitation is $600-800 \mathrm{~mm}$, the majority of which occurs from June to September, the annual relative humility is $56 \%$, and the frost-free period lasts for 92 days per year. The soil types in the region are cinnamon soil, mountain cinnamon soil, mountain leaching cinnamon soil, mountain brown soil, and sub-alpine meadow soil as the elevation goes from low to high $[24,25]$. From the foothill to the top of the mountain, the vegetation types are deciduous broad-leaved forest (1200-1750 m), mixed coniferous broad-leaved forest (1750-2200 m), cold-warm coniferous forest (2200-2600 m), and sub-alpine shrub meadow (2600-2720 m), in which sub-alpine meadow is the dominant type.

The experimental site was in the sub-alpine meadow zone $\left(37^{\circ} 53^{\prime} 08.5^{\prime \prime} \mathrm{N}, 111^{\circ} 32^{\prime} 18^{\prime \prime} \mathrm{E} ; 150 \mathrm{hm}^{2}\right)$ located at the top of the reserve, which is a typical mountain meadow in north China. The sub-alpine meadow was mainly composed of Kobresia bellardii and Carex lanceolata. The meadow grasses in the study area are luxuriant, with a grass layer height of $15-20 \mathrm{~cm}$. In addition, the organic matter content in the upper soil layer is $10 \%-15 \%$. 


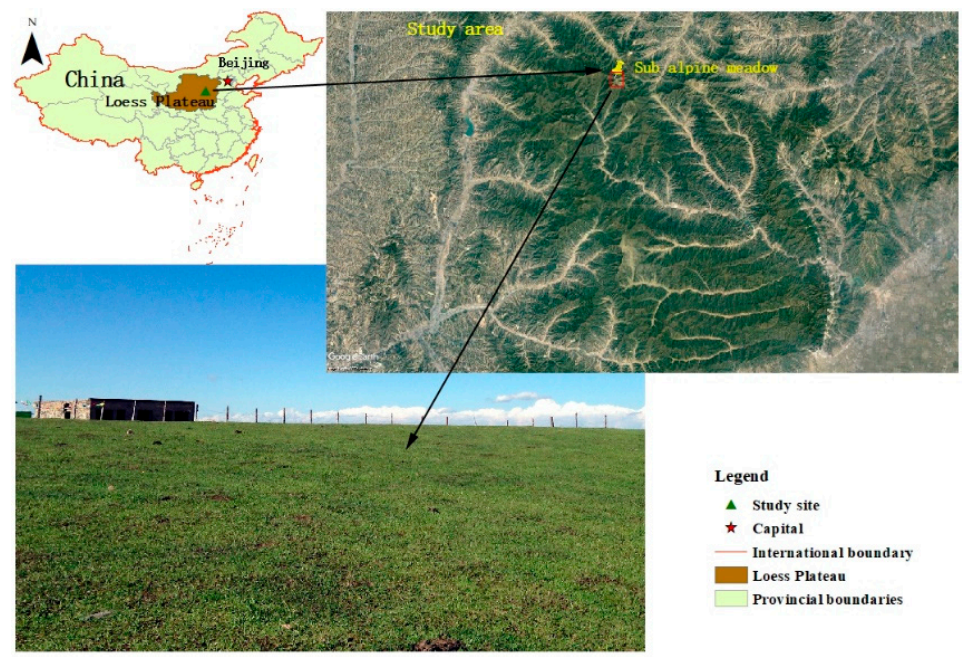

Figure 1. A sketch map of the study area in the Loess Plateau, China.

\subsection{Experimental Procedures and Measurement of $R_{S}$ and the Related Environmental Factors}

Soil respiration $\left(R_{\mathrm{S}}\right)$ was measured once a month during April to November from August 2007 to November 2015. The diurnal variation of $R_{\mathrm{S}}$ was measured to eliminate the influence of diurnal range on seasonal variations. The $R_{\mathrm{S}}$ rate between 8:00 and 11:00 AM was almost equal to the daily average $R_{\mathrm{S}}$ in the study site [26]. Thus the measurements were conducted during 9:00 to 11:00 local time to minimize the influence of the daytime temperature fluctuations. Furthermore, all measurements were conducted on rain-free days.

Soil respiration was measured using a LI-COR 6400 portable photosynthesis system (LI-COR, Environmental Division, Lincoln, NE, USA) equipped with a LI-COR 6400-09 soil chamber with an area of $71.6 \mathrm{~cm}^{2}$ that calculated soil $\mathrm{CO}_{2}$ efflux in the chamber using optical absorption spectroscopy in the infrared range. Detailed information regarding the system is available elsewhere [19]. The spatial heterogeneity of $R_{\mathrm{S}}$ at the study site has been studied previously [25,26], which facilitated design of the sampling strategy and determination of the optimal sample size for the study site. At least 15 collars from PVC pipe were inserted $2-3 \mathrm{~cm}$ into the soil and the soil chamber was mounted on each collar at the time of observation. Three cycles of consecutive measurements on the collar were conducted to prevent any systematic errors, and the average $R_{S}$ value was used for each collar. The plants were cut off inside the collars manually to avoid the effects of photosynthesis on $R_{\mathrm{s}}$. To minimize the effects of soil disturbance during installation, all collars were installed at least 1 day before measurement. Hence, it was assumed that there was no disturbance caused by operation of the flux chamber or plant growth. The average soil $\mathrm{CO}_{2}$ efflux rate from all PVC collar measurements was recorded as the mean daily $R_{s}$ at the measuring time in study site. The measuring frequency was once a month. The monthly $R_{S}$ was computed by averaging all daily measured data in the corresponding month from August 2007 to November 2015 ( $\mathrm{n}=4$ for April, 8 for May, 8 for June, 8 for July, 9 for August, 9 for September, 7 for October, and 5 for November) to get a representative monthly value. The frequency of the determination of related environmental factors were the same as for $R_{s}$.

The soil temperature $\left(T_{\mathrm{s}}\right)$ at depth of $5 \mathrm{~cm}$ was recorded using a thermocouple probe equipped with a portable photosynthesis system (LI-COR 6400) at locations near where $R_{\mathrm{s}}$ was measured. The soil moisture $\left(M_{\mathrm{s}}\right)$ was measured using soil samples collected from depths of $0-10 \mathrm{~cm}$ at the time of efflux measurement. Briefly, samples were returned to the laboratory and oven-dried at $105^{\circ} \mathrm{C}$ until a constant mass was reached, and $M_{\mathrm{s}}$ was expressed as a percentage of dry soil mass.

MODIS eight-day surface reflectance products and eight-day land surface temperature (LST) products (MOD09A1, $0.5 \mathrm{~km}$ and MOD11A2, $1 \mathrm{~km}$ ) in accordance with the in situ measuring time from NASA's Earth Observing System Data and Information System (https://wist.echo.nasa.gov/api//) were downloaded. To match the measuring time of $R_{\mathrm{s}}$, we obtained the LST and normalized 
difference vegetation index (NDVI) of the measuring day by linear interpolation of two consecutive eight-day spatial products. The pixel containing the study site was extracted based on the geo-location information (latitude and longitude). All the 15 or more sampling points in study site were in one pixel for retrieving the MODIS data based on the geo-location information. Each pixel contained the best possible observation coverage, low view angle, absence of clouds or cloud shadow and aerosol loading $[5,23]$.

The land surface temperature (MOD11A2, $1 \mathrm{~km}$ ) was derived by applying the generalized split-window algorithm $[5,27]$. The nighttime land surface temperature observed by MODIS onboard the Terra satellite is hereafter referred to as LST.

It is known that the most widely used normalized difference vegetation index (NDVI) is affected by soil reflectance in sparsely vegetated areas and saturates in cases of dense and multi-layered canopies [28]. The eight-day leaf area index (LAI) product (MOD15A2, $1 \mathrm{~km}$ ) derived from surface characteristics [5] such as reflectance, land cover type, and other ancillary information, was mostly less than three in the geographic unit of study site, demonstrating that the most widely used NDVI could be a more suitable indicator of vegetation biophysical parameters than the enhanced vegetation index (EVI). The value of the normalized vegetation index (NDVI) was calculated from the two wavelength bands of surface reflectance using the following formula [29]:

$$
\mathrm{NDVI}=\frac{\rho \mathrm{Nir}-\rho \operatorname{Red}}{\rho \mathrm{Nir}+\rho \operatorname{Red}}
$$

where $\rho_{\mathrm{Nir}}$ and $\rho_{\text {Red }}$ represent the reflectance for the near-infrared (MODIS band 2) and red (MODIS band 1) wavelength bands, respectively.

\subsection{Modeling Strategy}

All the monthly-measured data in each year was used for $R_{\mathrm{s}}$ model construction $(\mathrm{n}=58)$ to explore the relationship between $R_{\mathrm{s}}$ and environmental factors. Also, all measured or downloaded data were verified for assumptions of normality and variance homogeneity before conducting statistical analyses using the Kolmogorov-Smirnov test and Levene's test. In this study, a three-step reliable model was developed to quantify the temporal variations of $R_{\mathrm{S}}$ within environmental factors. First, a one-factor equation was constructed to study the relationship between $R_{\mathrm{s}}$ and temperature or vegetation index:

$$
\begin{gathered}
R_{s}=a T+b \\
R_{s}=a e^{b T}, \mathrm{Q}_{10}=e^{10 b} \text { and } \mathrm{R}_{10}=a e^{10 b} \\
R_{s}=a \mathrm{NDVI}+b \\
R_{s}=a e^{b \mathrm{NDVI}} .
\end{gathered}
$$

Second, a bivariate equation was constructed by adding another independent variable:

$$
\begin{gathered}
R_{s}=a L S T+b \mathrm{NDVI}+c \\
R_{\mathrm{s}}=a \exp (b \mathrm{LST}+c \mathrm{NDVI}) \\
R_{S}=a M_{s}+b M_{\mathrm{s}}^{2}+c T_{s}+d . \\
R_{\mathrm{S}}=a \exp \left(b M_{S}+c M_{s}^{2}+d T_{\mathrm{s}}\right) .
\end{gathered}
$$

Finally, a fitting model of the $R_{\mathrm{s}}$ temporal variation is formulated by compounding all three kinds of variables:

$$
\begin{gathered}
R_{s}=a M_{\mathrm{s}}+b M_{\mathrm{s}}^{2}+c T+d \mathrm{NDVI}+e \\
R_{\mathrm{s}}=a \exp \left(b M_{s}+c M_{\mathrm{s}}^{2}+d T+e \mathrm{NDVI}\right)
\end{gathered}
$$


where $R_{\mathrm{s}}$ is the soil respiration rate $\left(\mu \mathrm{mol} \mathrm{CO} \mathrm{CO}^{-2} \mathrm{~s}^{-1}\right), \mathrm{T}$ is the soil temperature $\left({ }^{\circ} \mathrm{C}\right)$ or land surface temperature $\left({ }^{\circ} \mathrm{C}\right), M_{\mathrm{S}}$ is the soil moisture (\%), NDVI is the vegetation index, and $\mathrm{a}, \mathrm{b}, \mathrm{c}, \mathrm{d}$, and e are fitting parameters. $\mathrm{Q}_{10}$ is the temperature sensitivity index of $R_{\mathrm{S}}$, indicating the proportional change in $R_{\mathrm{S}}$ for $10^{\circ} \mathrm{C}$ increase in temperature, while $R_{10}$ is the soil respiration rate at a soil temperature of $10{ }^{\circ} \mathrm{C}$, i.e., soil basal respiration. This value is widely applied for comparison of $R_{\mathrm{S}}$ among ecosystems.

The fitness and accuracy of the model were evaluated by three standards: the coefficient of determination $\left(R^{2}\right)$, root-mean-square error (RMSE), and Akaike's information criterion (AIC) [23], where $\mathrm{R}^{2}$ can be directly obtained by SPSS 17.0. The two remaining indexes were calculated as follows:

$$
\begin{gathered}
\mathrm{RMSE}=\sqrt{\mathrm{RSS} / \mathrm{n}} \\
\mathrm{AIC}=\mathrm{nlnRSS}+2(\mathrm{p}+1)-\mathrm{nlnn},
\end{gathered}
$$

where RSS is the residual sum of squares, $\mathrm{n}$ is the sample size, and $\mathrm{p}$ is the number of independent variables. The main environmental factor driving $R_{\mathrm{s}}$ temporal variation and the optimal fitting model was selected based on the higher $R^{2}$ and the lower RMSE and AIC.

All statistical analyses were performed using the Statistical Package for the Social Sciences (SPSS 17.0) (SPSS Inc., Chicago, IL, USA) and graphs were generated with SigmaPlot 12.5 (Systat Software, Inc., San Jose, CA, USA).

\section{Results}

\subsection{Seasonal Variations in $R_{S}$}

An overall preliminary correlation analysis showed that the soil temperature $\left(T_{\mathrm{s}}\right)$ at $5 \mathrm{~cm}$ and nighttime land surface temperature (LST) observed by MODIS onboard the Terra satellite correlated with soil respiration $\left(R_{\mathrm{S}}\right)$ best among all investigated temperature factors; therefore, we chose these two indexes as the representative temperature factors relating to $R_{\mathrm{s}}$. As shown in Figure 2, during the measuring year, seasonal variations of $R_{\mathrm{S}}, T_{\mathrm{s}}, \mathrm{NDVI}$, and LST were similar, with all of these generating an approximately symmetrical bell type distribution along the temporal scale. Owing to the effects of solar radiation, $T_{\mathrm{S}}$ was lowest in winter and spring $\left(5.18 \pm 2.36{ }^{\circ} \mathrm{C}\right.$ in April) (mean $\pm \mathrm{SE}$ ), after which it dramatically increased as solar radiation and air temperature increased, reaching the highest value by the end of June and early July $\left(17.38 \pm 0.67^{\circ} \mathrm{C}\right) . T_{\mathrm{s}}$ began to decrease in late July, with the greatest rate of decrease occurring from September to October. Additionally, the monthly coefficient of variation $(\mathrm{CV})$ of $T_{\mathrm{S}}$ was comparatively higher in the phenological phase of the beginning and late growing period, while it maintained a low and steady value in the growing season (Figure 3). Under the influence of solar radiation and surface reflection, the seasonal variations in LST were in accordance with $T_{\mathrm{s}}$, but comparatively lower. The maximum value of NDVI appeared from July to August, while its mean value during the measuring period was $0.55 \pm 0.18$ (mean $\pm \mathrm{SE}$ ), which was comparatively lower than other types of ecosystems (Figure 2c). In addition, the monthly CV of the NDVI was relatively low, being almost below $20 \%$ during each month. The seasonal dynamics of soil moisture $\left(M_{\mathrm{s}}\right)$ throughout the measuring period were not as pronounced as those for the other factors mentioned above. Rather, $M_{\mathrm{s}}$ showed a fluctuating pattern, accompanied by a trend of high and low alternations that varied significantly in response to natural precipitation. Overall, $M_{\mathrm{s}}$ was lower in late spring and early summer and higher in mid-summer, autumn and winter, with a mean value during the measuring period of $45.57 \% \pm 8.09 \%$. The monthly CVs of $M_{\mathrm{S}}$ and NDVI appeared to have a high and low fluctuating state within a small range, ranging from $6 \%$ in November to $31 \%$ in July for $M_{\mathrm{S}}$ and from $5 \%$ in October to $29 \%$ in November for NDVI (Figure 3). 

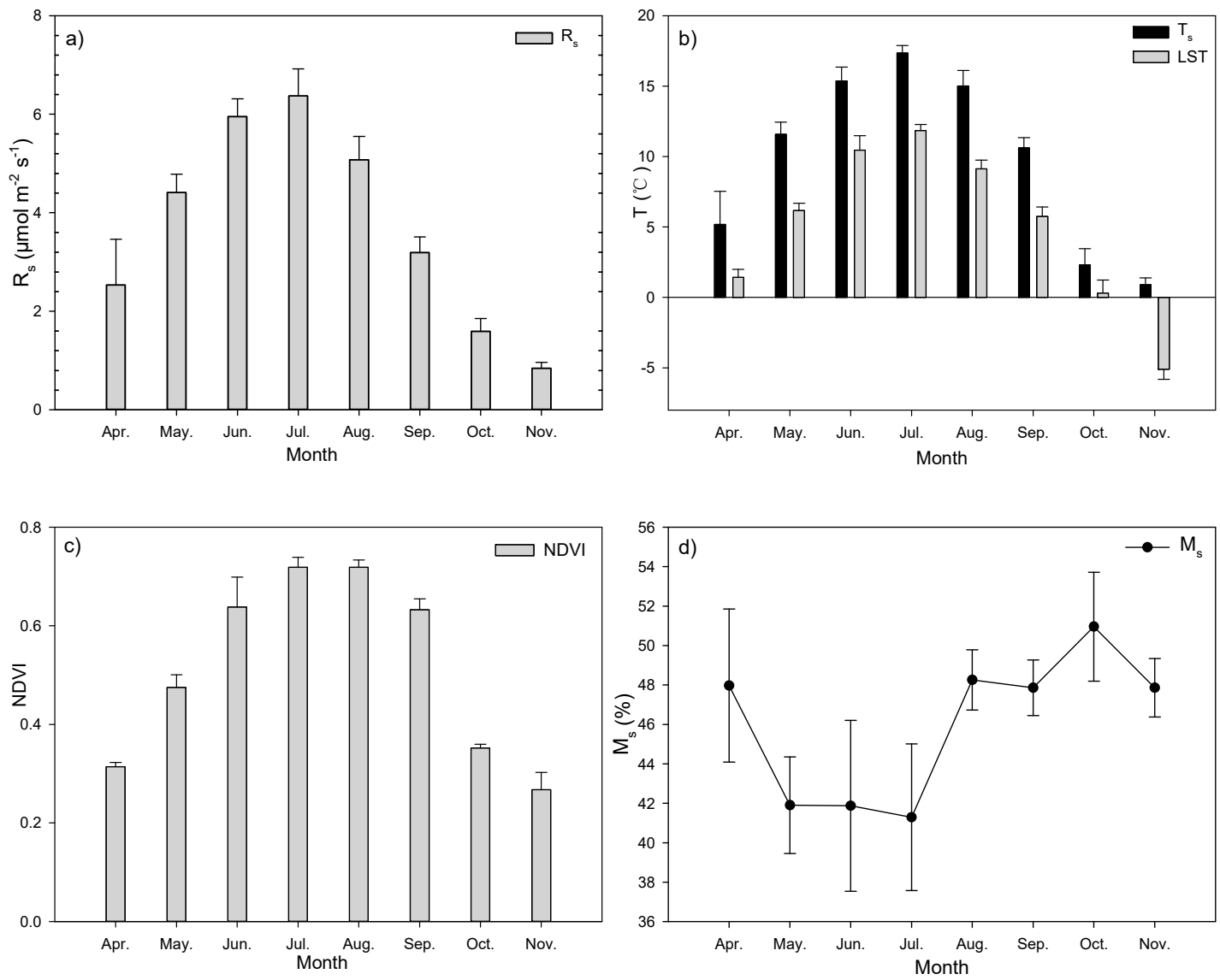

Figure 2. Seasonal dynamics of (a) soil respiration $\left(R_{s}\right),(\mathbf{b})$ soil temperature $\left(T_{\mathrm{s}}\right)$, nighttime land surface temperature (LST) observed by Terra satellite, (c) normalized difference vegetation index (NDVI), and $(\mathbf{d})$ soil moisture $\left(M_{\mathrm{S}}\right)$ in the sub-alpine meadow from 2007 to 2015.

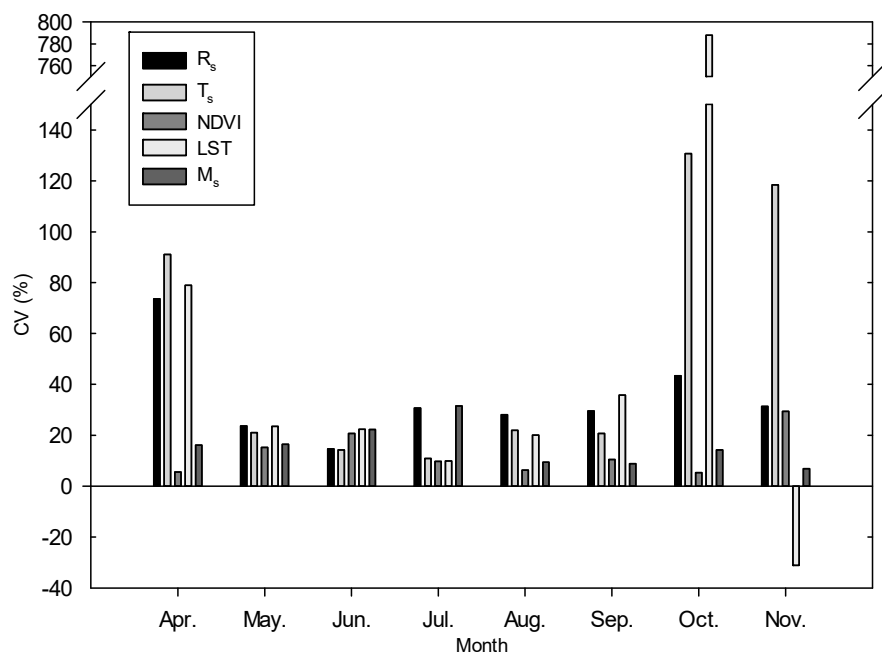

Figure 3. The monthly coefficient of variation $(\mathrm{CV})$ of soil respiration $\left(R_{\mathrm{s}}\right)$, soil temperature $\left(T_{\mathrm{s}}\right)$, nighttime land surface temperature (LST) observed by Terra satellite, normalized difference vegetation index (NDVI), and soil moisture $\left(M_{\mathrm{s}}\right)$ from 2007 to 2015.

Soil respiration exhibited an obvious bell type seasonal variation similar to $T_{\mathrm{S}}$ or LST, clearly illustrating the dynamics of $R_{\mathrm{S}}$ were closely related to temperature with time at the site. The $R_{\mathrm{S}}$ value was lower in the early growing season $\left(1-2 \mu \mathrm{mol} \mathrm{CO} \mathrm{CO}^{-2} \mathrm{~s}^{-1}\right)$, after which it gradually increased because of the rising temperature and biomass $\left(4-8 \mu \mathrm{mol} \mathrm{CO} \mathrm{CO}_{2}^{-2} \mathrm{~s}^{-1}\right)$, peaking at over $7 \mu \mathrm{mol}$ 
$\mathrm{CO}_{2} \mathrm{~m}^{-2} \mathrm{~s}^{-1}$ in June and July. After that, $R_{\mathrm{s}}$ tapered gradually to less than $1 \mu \mathrm{mol} \mathrm{CO}_{2} \mathrm{~m}^{-2} \mathrm{~s}^{-1}$ in November. The mean value was $4.17 \pm 0.29 \mu \mathrm{mol} \mathrm{CO}_{2} \mathrm{~m}^{-2} \mathrm{~s}^{-1}$ during the nine-year observation period. Additionally, the monthly CV of $R_{\mathrm{s}}$ exhibited a wave curve with time, ranging from $14 \%$ in June to $73 \%$ in April, with the maximum occurring in the spring and winter and the range being relatively smaller from May to November. The $R_{\mathrm{s}}$ rate presented a more stable state in June, when the CV was lowest (Figure 2a, Figure 3).

\subsection{Modeling $R_{S}$ Seasonal Variations}

The relationship between $R_{\mathrm{s}}$ and environmental factors can be expressed by linear, exponential, double exponential, power, hyperbolic curve, quadratic, and Lloyd and Taylor models, as well as their composites. The linear and exponential models expressed the relationships between $R_{\mathrm{S}}$ and temperature or vegetation cover well. The model with the best fit was selected by comparing three model performance indicators $\left(\mathrm{R}^{2}, \mathrm{RMSE}, \mathrm{AIC}\right)$. For the response of $R_{\mathrm{S}}$ to $M_{\mathrm{S}}$, the quadratic equation had a better empirical fit. Correlation analyses showed that there was an extremely significantly positive correlation between $R_{\mathrm{s}}$ and $T_{\mathrm{S}}\left(\mathrm{r}=0.896^{* *}\right)$, LST $\left(\mathrm{r}=0.834^{* *}\right)$ and NDVI $\left(\mathrm{r}=0.753^{* *}\right)$ (Table 1$)$, but no significant correlation between $R_{\mathrm{s}}$ and $M_{\mathrm{s}}$. Overall, for the same environmental factors, the exponential model fitted better than the linear form, with higher $\mathrm{R}^{2}$ and lower RMSE and AIC values (Table 2). The exponential model based entirely on in situ measured $T_{\mathrm{S}}\left(\mathrm{R}^{2}=0.842, p<0.001\right)$ showed a relatively higher explanation capacity than the exponential model based on LST $\left(R^{2}=0.762\right.$, $p<0.001)$. The further addition of $M_{\mathrm{S}}$ explained an additional $1.3 \%$ of the $R_{\mathrm{S}}$ seasonal variation based on the $T_{\mathrm{s}}$ linear model and $0.8 \%$ of the $R_{\mathrm{s}}$ seasonal variation based on the $T_{\mathrm{s}}$ exponential model. The model based entirely on the plant photosynthesis-related NDVI exhibited the poorest fit for $R_{\mathrm{S}}$ $\left(R^{2}=0.568\right.$ for the linear model, and $R^{2}=0.605$ for the exponential model). However, the addition of LST improved the explanation by $15 \%$ for the linear model and $17.7 \%$ for the exponential model. Taking $M_{\mathrm{s}}$, temperature and NDVI into account together, the explanation of the model showed a slight improvement relative to the exponential models with two variables. Overall, the model based on the in situ observed data had a slightly higher explanation than the model based on the spatial products, with higher $R^{2}$ values and lower RMSE and AIC values. Considering that the three model performing indicators of three exponential models with good fitting effects (based on $T_{\mathrm{S}}$, both $T_{\mathrm{S}}$ and $M_{\mathrm{s}}$, and together with $M_{\mathrm{s}}, T_{\mathrm{s}}$, and NDVI) showed minor differences and the models all reached significant levels, we selected the simplest exponential model based on $T_{\mathrm{S}}$ as the optimum fitting model to describe seasonal variations in $R_{\mathrm{s}}$.

Table 1. Correlation coefficients $(\mathrm{r})$ and $p$ values between soil respiration $\left(R_{\mathrm{s}}\right)$ and its related factors.

\begin{tabular}{lllllll}
\hline $\boldsymbol{R}_{\mathbf{s}}$ & & $\boldsymbol{R}_{\mathbf{s}}$ & $\boldsymbol{T}_{\mathbf{s}}$ & $\boldsymbol{M}_{\mathbf{s}}$ & LST & NDVI \\
\hline & $\mathrm{r}$ & 1.000 & $0.896^{* *}$ & -0.183 & $0.834^{* *}$ & $0.753^{* *}$ \\
& $p$ value & & 0.000 & 0.169 & 0.000 & 0.000 \\
\hline
\end{tabular}

** Correlation is significant at 0.01 level (two-tailed); $\mathrm{n}=58 . R_{\mathrm{S}}$ is measured soil respiration $\left(\mu \mathrm{mol} \mathrm{CO}_{2} \mathrm{~m}^{-2} \mathrm{~s}^{-1}\right), T_{\mathrm{s}}$ is soil temperature $\left({ }^{\circ} \mathrm{C}\right)$, LST is the nighttime land surface temperature observed by the Moderate Resolution Imaging Spectro radiometer (MODIS) onboard terra satellite $\left({ }^{\circ} \mathrm{C}\right)$, and NDVI is the normalized difference vegetation index.

Table 2. Regression analysis relating soil respiration $\left(R_{\mathrm{S}}\right)$ to soil temperature $\left(T_{\mathrm{S}}\right)$, soil moisture $\left(M_{\mathrm{S}}\right)$, land surface temperature (LST), and the normalized difference vegetation index (NDVI).

\begin{tabular}{|c|c|c|c|c|c|}
\hline \multicolumn{2}{|c|}{ Models and Equations } & \multirow{2}{*}{$\frac{\mathbf{R}^{\mathbf{2}}}{0.803^{* * *}}$} & \multirow{2}{*}{$\begin{array}{c}\text { RSS } \\
56.286\end{array}$} & \multirow{2}{*}{$\begin{array}{c}\text { RMSE } \\
0.985\end{array}$} & \multirow{2}{*}{$\begin{array}{c}\text { AIC } \\
2.260\end{array}$} \\
\hline & (1) $R_{\mathrm{s}}=a T_{\mathrm{s}}+b$ & & & & \\
\hline$R_{\mathrm{s}}=f\left(I_{\mathrm{s}}\right)$ & (2) $R_{\mathrm{S}}=a e^{b T_{\mathrm{s}}}$ & $0.842 * * *$ & 4.742 & 0.286 & -141.231 \\
\hline \multirow{2}{*}{$R_{\mathrm{s}}=f\left(M_{\mathrm{s}} \cdot T_{\mathrm{s}}\right)$} & (1) $R_{\mathrm{s}}=a M_{s}+b M_{\mathrm{s}}^{2}+c T_{s}+d$ & $0.816^{* * *}$ & 52.61 & 0.952 & 0.343 \\
\hline & (2) $R_{\mathrm{S}}=a \exp \left(b M_{\mathrm{s}}+c M_{\mathrm{s}}^{2}+d T_{\mathrm{s}}\right)$ & $0.850 * * *$ & 4.499 & 0.279 & -142.282 \\
\hline \multirow[t]{2}{*}{$R_{\mathrm{S}}=f(\mathrm{LST})$} & (1) $R_{\mathrm{S}}=a \mathrm{LST}+b$ & $0.695^{* * *}$ & 87.135 & 1.226 & 27.607 \\
\hline & $\begin{array}{l}\text { (2) } R_{\mathrm{s}}=a e^{b \mathrm{LST}} \\
(1) R_{\mathrm{s}}=e \mathrm{NDI}+b\end{array}$ & $0.762^{* * *}$ & $\begin{array}{c}7.135 \\
123701\end{array}$ & $\begin{array}{l}0.351 \\
1.460\end{array}$ & -117.535 \\
\hline$R_{\mathrm{s}}=f(\mathrm{NDVI})$ & $\begin{array}{l}\text { (1) } R_{\mathrm{S}}=a \mathrm{NDVV}+b \\
\text { (2) } R_{\mathrm{S}}=a e^{b \mathrm{NDVI}}\end{array}$ & $0.605^{* * *}$ & $\begin{array}{l}123.01 \\
11.823\end{array}$ & 0.451 & -88.243 \\
\hline
\end{tabular}


Table 2. Cont.

\begin{tabular}{|c|c|c|c|c|c|}
\hline \multicolumn{2}{|c|}{ Models and Equations } & $\mathbf{R}^{2}$ & RSS & RMSE & AIC \\
\hline \multirow{2}{*}{$R_{\mathrm{S}}=f(\mathrm{LST} \cdot \mathrm{NDVI})$} & (1) $R_{\mathrm{s}}=a \mathrm{LST}+b \mathrm{NDVI}+c$ & $0.718^{* * *}$ & 80.562 & 1.179 & 25.058 \\
\hline & (2) $R_{\mathrm{S}}=a \exp (b \mathrm{LST}+c \mathrm{NDVI})$ & $0.782 * * *$ & 6.537 & 0.336 & -120.612 \\
\hline \multirow{2}{*}{$R_{\mathrm{s}}=f\left(M_{\mathrm{s}} \cdot T_{\mathrm{s}} \cdot \mathrm{NDVI}\right)$} & (1) $R_{\mathrm{s}}=a M_{\mathrm{s}}+b M_{\mathrm{s}}^{2}+c T_{\mathrm{s}}+d \mathrm{NDVI}+e$ & $0.817^{* * *}$ & 52.419 & 0.951 & 2.132 \\
\hline & (2) $R_{\mathrm{s}}=a \exp \left(b M_{s}+c M_{\mathrm{s}}^{2}+d T_{\mathrm{s}}+e \mathrm{NDVI}\right)$ & $0.854 * * *$ & 4.364 & 0.274 & -142.049 \\
\hline \multirow{2}{*}{$R_{\mathrm{S}}=f\left(M_{\mathrm{s}} \cdot \mathrm{LST} \cdot \mathrm{NDVI}\right)$} & (1) $R_{\mathrm{s}}=a M_{\mathrm{s}}+b M_{\mathrm{s}}^{2}+c \mathrm{LST}+d \mathrm{NDVI}+e$ & $0.748^{* * *}$ & 72.085 & 1.115 & 20.609 \\
\hline & (2) $R_{\mathrm{s}}=a \exp \left(b M_{s}+c M_{s}^{2}+d \mathrm{LST}+e \mathrm{NDVI}\right)$ & $0.819^{* * *}$ & 5.431 & 0.306 & -129.363 \\
\hline
\end{tabular}

$\mathrm{R}^{2}$ is the coefficient of determination, RMSE $\left(\mu \mathrm{mol} \mathrm{CO} \mathrm{m}^{-2} \mathrm{~s}^{-1}\right.$ ) is the root-mean-square error, and AIC is the Akaik's information criterion. ${ }^{* * *}$ means the relationships are statistically significant at $p<0.001 . R_{\mathrm{S}}$ is measured soil respiration ( $\mu \mathrm{mol} \mathrm{CO} \mathrm{C}^{-2} \mathrm{~s}^{-1}$ ), $T_{\mathrm{s}}$ is soil temperature $\left({ }^{\circ} \mathrm{C}\right)$, LST is the nighttime land surface temperature observed by the Moderate Resolution Imaging Spectro radiometer (MODIS) onboard terra satellite $\left({ }^{\circ} \mathrm{C}\right.$ ), and NDVI is the normalized difference vegetation index.

There was a small gap in the explanation capacity between the LST exponential model and the $T_{\mathrm{S}}$ exponential model, and the Pearson correlation coefficient was 0.902 between $T_{\mathrm{S}}$ and LST data (Figure 4). A univariate exponential model based on $T_{\mathrm{S}}$ and LST was then constructed for each year (Table 3). The $t$-test analysis of the three model performance indicators of two univariate exponential models for each year produced no significant differences. Therefore, the LST exponential model based on complete remote sensing data could be used as an empirical fitting model to modify seasonal variations in $R_{\mathrm{s}}$.

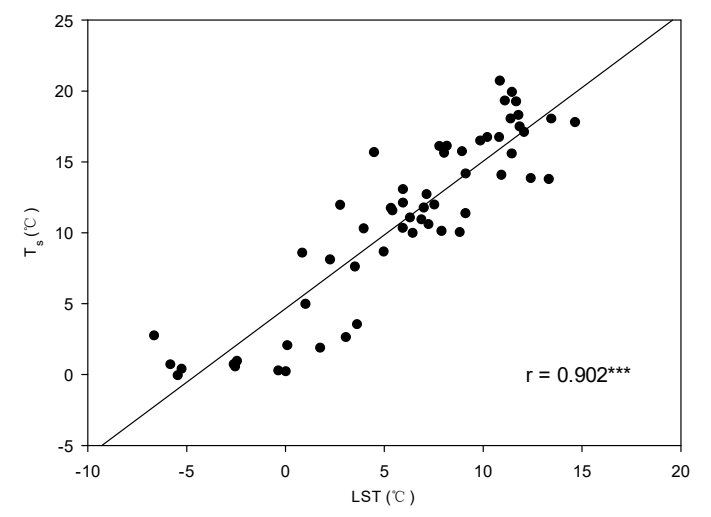

Figure 4. Relationships between soil temperature $\left(T_{\mathrm{s}}\right)$ and land surface temperature (LST) in study site from 2007 to $2015(\mathrm{n}=58)$. ${ }^{* * *}$ means the relationships are statistically significant at $p<0.001$.

Table 3. The model evaluation index of two univariate exponential models in each year in the study site.

\begin{tabular}{cccccccccc}
\hline & $\mathbf{2 0 0 8}$ & $\mathbf{2 0 0 9}$ & $\mathbf{2 0 1 0}$ & $\mathbf{2 0 1 1}$ & $\mathbf{2 0 1 2}$ & $\mathbf{2 0 1 3}$ & $\mathbf{2 0 1 4}$ & $\mathbf{2 0 1 5}$ & $\mathbf{2 0 0 7 - 2 0 1 5}$ \\
\hline $\mathrm{R}^{2}{ }_{1}$ & 0.907 & 0.601 & 0.885 & 0.941 & 0.676 & 0.797 & 0.913 & 0.923 & 0.842 \\
$\mathrm{R}^{2}$ & 0.947 & 0.554 & 0.688 & 0.984 & 0.704 & 0.657 & 0.892 & 0.757 & 0.762 \\
$\mathrm{RMSE}_{1}$ & 0.211 & 0.330 & 0.216 & 0.221 & 0.326 & 0.282 & 0.252 & 0.179 & 0.286 \\
$\mathrm{RMSE}_{2}$ & 0.159 & 0.350 & 0.384 & 0.122 & 0.336 & 0.396 & 0.304 & 0.366 & 0.351 \\
$\mathrm{AIC}_{1}$ & -14.674 & -9.289 & -17.425 & -17.152 & -11.710 & -13.705 & -15.289 & -23.567 & -141.231 \\
$\mathrm{AIC}_{2}$ & -18.054 & -8.614 & -10.461 & -26.477 & -12.352 & -10.040 & -13.730 & -14.391 & -117.535 \\
\hline
\end{tabular}

$\mathrm{R}^{2}$ was the determination coefficient of the model and it reached 0.05 significance level in each year. RMSE $(\mu \mathrm{mol}$ $\mathrm{CO}_{2} \mathrm{~m}^{-2} \mathrm{~s}^{-1}$ ) was the root-mean-square error, and AIC was the Akaik's information criterion. Subscript 1 relates to the exponential equation based on $T_{s}$; and subscript 2 relates to the exponential equation based on LST.

The modeling accuracy of the $R_{\mathrm{s}}$ predictive models based on the $T_{\mathrm{S}}$ exponential equation and LST exponential equation is presented in Figure 5 ( $a$ for $T_{\mathrm{s}} ; \mathrm{b}$ for LST). Pearson's correlation coefficient was $0.862^{* *}$ between the measured $R_{\mathrm{S}}$ and predicted $R_{\mathrm{s}}$ based on $T_{\mathrm{s}}$ and $0.807^{* *}$ between the measured $R_{\mathrm{S}}$ and predicted $R_{\mathrm{S}}$ based on the LST, verifying that the $T_{\mathrm{S}}$ and LST data were both effective and reliable for prediction of the temporal variations in $R_{\mathrm{s}}$ in the study site. 

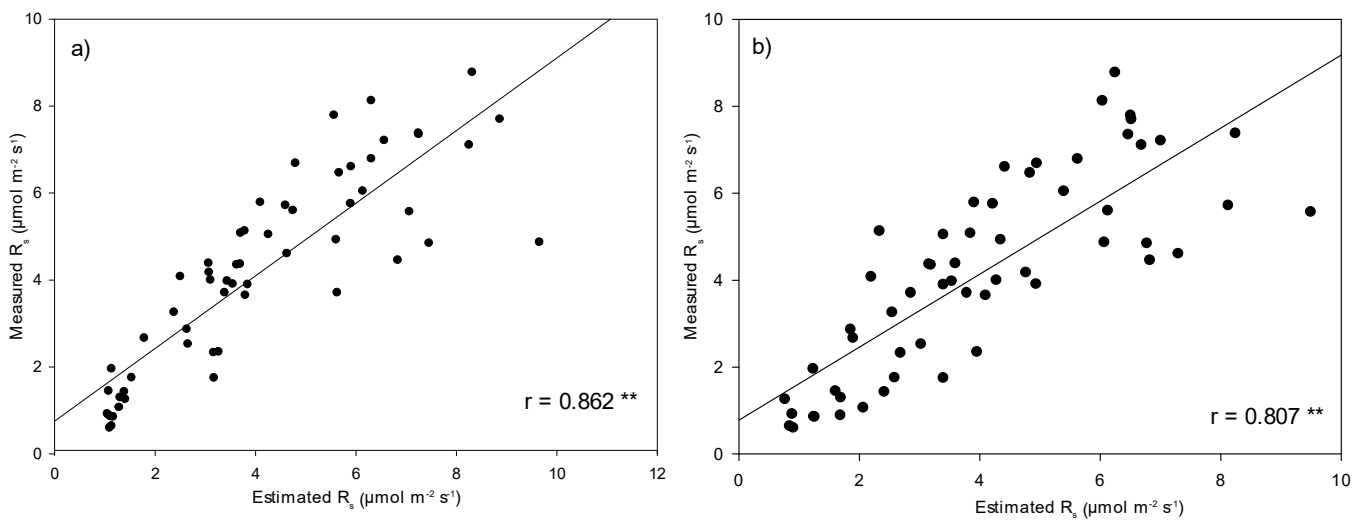

Figure 5. The relationship between measured soil respiration (measured $R_{\mathrm{S}}$ ) and (a) $T_{\mathrm{S}}$ exponential model estimated soil respiration (estimated $R_{\mathrm{S}}$ ), and (b) LST exponential model estimated soil respiration (estimated $R_{\mathrm{S}}$ ). ${ }^{* *}$ correlation is significant at 0.01 level (two-tailed).

\subsection{Temperature Sensitivity of $R_{S}$}

The seasonal trend of $\mathrm{Q}_{10}$ and other climatic factors differed. Specifically, the monthly $T_{\mathrm{s}}$ and $R_{\mathrm{s}}$ increased from April $\left(5.18 \pm 2.34{ }^{\circ} \mathrm{C}, 2.53 \pm 0.93 \mu \mathrm{mol} \mathrm{CO} \mathrm{CO}^{-2} \mathrm{~s}^{-1}\right)$ to July $\left(17.38 \pm 0.67^{\circ} \mathrm{C}\right.$, $\left.6.29 \pm 0.68 \mu \mathrm{mol} \mathrm{CO}_{2} \mathrm{~m}^{-2} \mathrm{~s}^{-1}\right)$, after which they decreased to the lowest values in November $\left(0.91 \pm 0.48^{\circ} \mathrm{C}, 0.84 \pm 0.12 \mu \mathrm{mol} \mathrm{CO} \mathrm{CO}^{-2} \mathrm{~s}^{-1}\right)$ (Figure 6). The $\mathrm{Q}_{10}$ seasonal trend was contrary to the corresponding $T_{\mathrm{S}}$ and $R_{\mathrm{s}}$ trends, presenting a concave type distribution. Moreover, its value was higher in cold months and lower in warm months. The $\mathrm{Q}_{10}$ value decreased from April (4.31) to September (1.27), then increased dramatically until peaking in November (7.03). The seasonal $R_{10}$ trend fluctuated, but its values basically remained around $4 \mu \mathrm{mol} \mathrm{CO} \mathrm{C}^{-2} \mathrm{~s}^{-1}$ during each month.
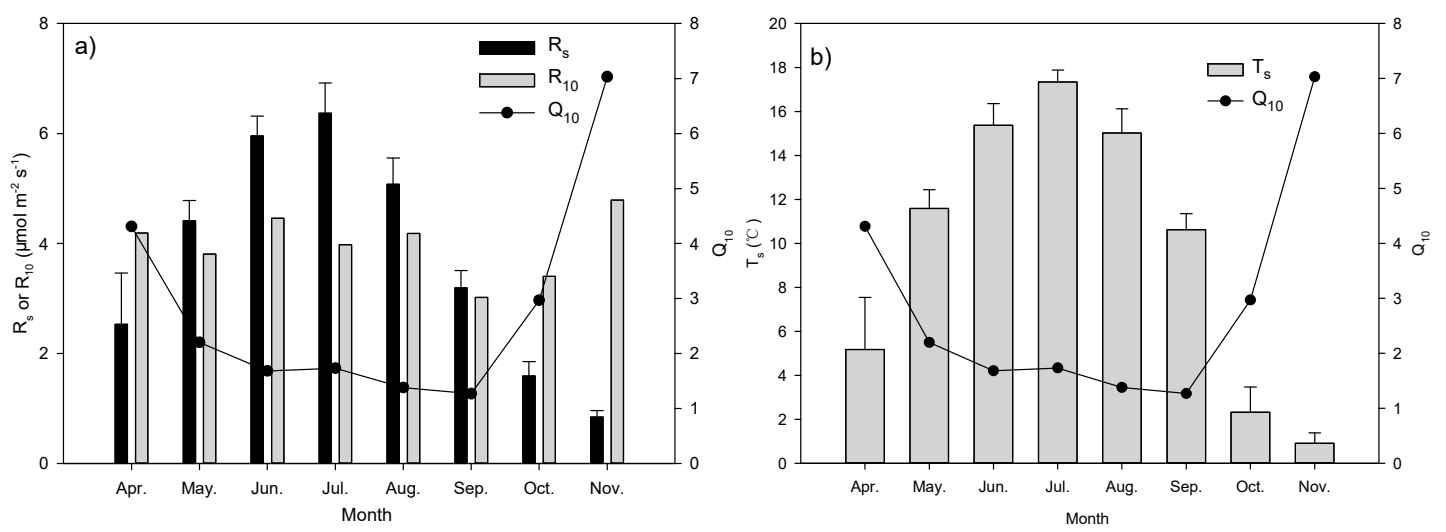

Figure 6. Seasonal variation of the monthly mean temperature sensitivity $\left(\mathrm{Q}_{10}\right)$ with (a) soil respiration $\left(R_{\mathrm{s}}\right)$, reference soil respiration $\left(\mathrm{R}_{10}\right)$, and $(\mathbf{b})$ soil temperature $\left(T_{\mathrm{S}}\right)$ from 2007 to 2015 in study site. Error bars indicate the standard error.

Under different temperature conditions, $\mathrm{Q}_{10}$ presented obviously different values (Figure 7). Specifically, as temperatures decreased, $\mathrm{Q}_{10}$ became higher. At the temperature interval of $-1{ }^{\circ} \mathrm{C}$ to $5^{\circ} \mathrm{C}$, the $\mathrm{Q}_{10}$ value was 7.61 , with a mean $T_{\mathrm{s}}$ of $1.5^{\circ} \mathrm{C}$ and a mean $R_{\mathrm{s}}$ of $1.25 \mu \mathrm{mol} \mathrm{CO} \mathrm{CO}^{-2} \mathrm{~s}^{-1}$. The $Q_{10}$ then decreased dramatically with the same temperature interval, i.e., $Q_{10}$ value of 0.67 for a temperature interval of $5{ }^{\circ} \mathrm{C}-11^{\circ} \mathrm{C}$ (mean $T_{\mathrm{s}}$ of $9.53^{\circ} \mathrm{C}, R_{\mathrm{s}}$ of $3.21 \mu \mathrm{mol} \mathrm{CO} \mathrm{Cm}^{-2} \mathrm{~s}^{-1}$ ), 1.79 for a temperature interval of $11^{\circ} \mathrm{C}-16^{\circ} \mathrm{C}$ (mean $T_{\mathrm{s}}$ of $13.18^{\circ} \mathrm{C}, R_{\mathrm{S}}$ of $4.86 \mu \mathrm{mol} \mathrm{CO}_{2} \mathrm{~m}^{-2} \mathrm{~s}^{-1}$ ), and 1.28 for $16^{\circ} \mathrm{C}-21{ }^{\circ} \mathrm{C}$ (mean $T_{\mathrm{s}}$ of $17.84{ }^{\circ} \mathrm{C}, R_{\mathrm{S}}$ of $6.29 \mu \mathrm{mol} \mathrm{CO} \mathrm{Cm}^{-2} \mathrm{~s}^{-1}$ ). Overall, $R_{\mathrm{S}}$ was extremely sensitive to temperature changes at lower temperatures. 

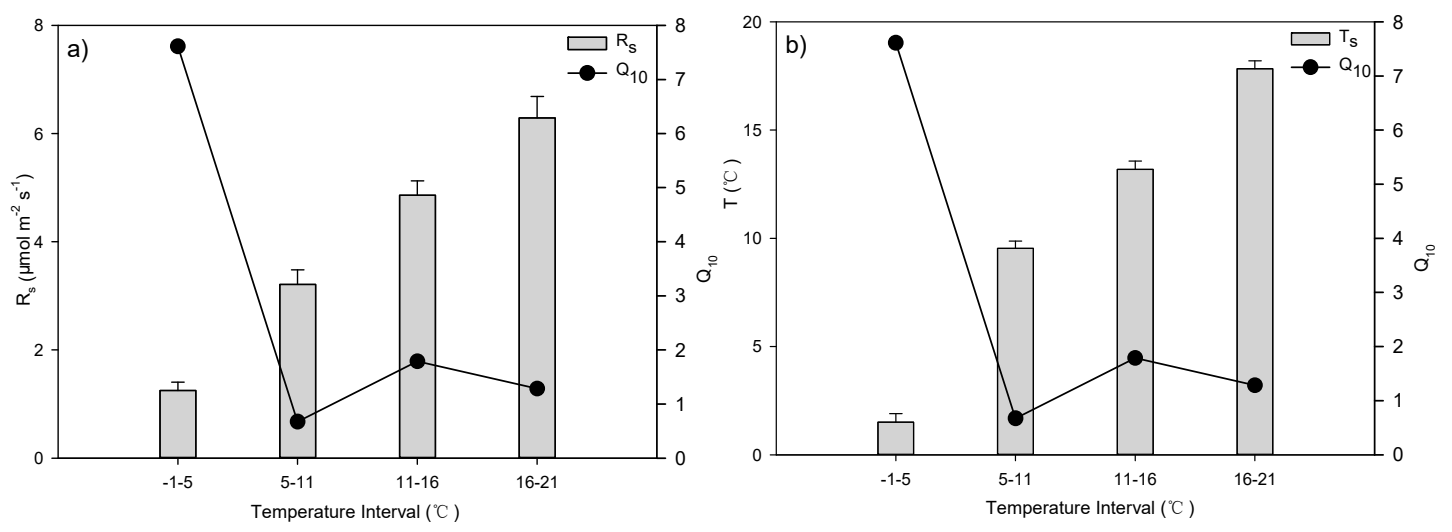

Figure 7. Temperature sensitivity of soil respiration $\left(\mathrm{Q}_{10}\right)$ with (a) soil respiration $\left(R_{\mathrm{S}}\right)$ and (b) soil temperature $\left(T_{\mathrm{S}}\right)$ in different temperature intervals. Error bars indicate the standard errors.

The $\mathrm{R}_{10}$ values in each year presented a fluctuating trend, ranging from a minimum of $2.57 \mu \mathrm{mol}$ $\mathrm{CO}_{2} \mathrm{~m}^{-2} \mathrm{~s}^{-1}$ in 2014 to a maximum of $3.39 \mu \mathrm{mol} \mathrm{CO}_{2} \mathrm{~m}^{-2} \mathrm{~s}^{-1}$ in 2013. The $\mathrm{CV}$ value was $9 \%$ during the nine-year observation period (Figure 8). Additionally, the mean annual $\mathrm{R}_{10}$ was $3.01 \pm 0.27 \mu \mathrm{mol} \mathrm{CO}_{2}$ $\mathrm{m}^{-2} \mathrm{~s}^{-1}$. The annual $\mathrm{Q}_{10}$ values showed a trend of fluctuation as well, but its range was greater than that of $R_{10}$, with a minimum of 1.84 being observed in 2009 and a maximum of 3.78 in 2011 . The yearly $\mathrm{CV}$ was $20 \%$ and the mean value of $\mathrm{Q}_{10}$ during the study year was $2.90 \pm 0.59$. Overall, although the $R_{10}$ and $Q_{10}$ values differed during each observed year, they were close to the mean values, except in 2009, when there was a water stress during the summer. This water shortage led to especially strong variations in $\mathrm{Q}_{10}$.

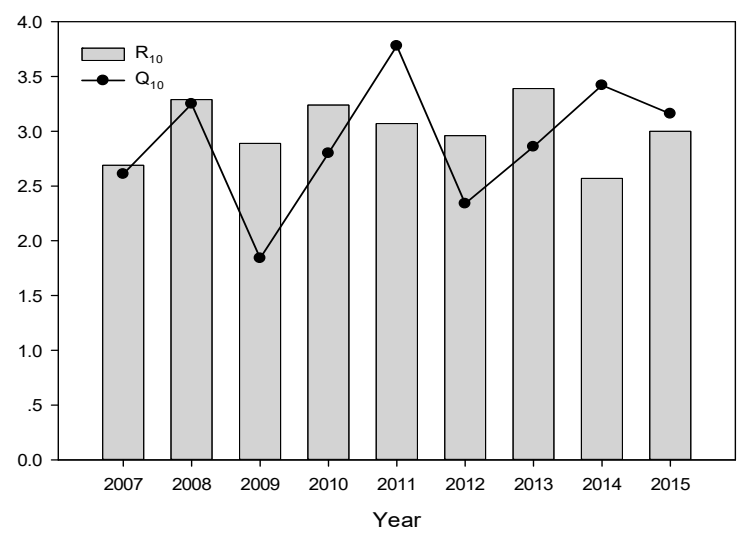

Figure 8. Reference soil respiration $\left(\mathrm{R}_{10}\right)$ and temperature sensitivity of soil respiration $\left(\mathrm{Q}_{10}\right)$ derived from the exponential equations in each year.

\section{Discussion}

\subsection{Seasonal Variations in $R_{s}$}

The seasonal patterns of $R_{s}, T_{\mathrm{S}}, \mathrm{LST}$, and NDVI all showed symmetrical bell type distributions, while $M_{\mathrm{S}}$ fluctuated during the nine-year measuring time. The variation in $R_{S}$ was consistent with that of the temperature $\left(T_{\mathrm{s}}, \mathrm{LST}\right)$, illustrating that temperature could explain most of the temporal variation of $R_{s}$. Mo et al. [30] observed a similar trend in the daily mean soil temperature at $1 \mathrm{~cm}$ depth and daily $\mathrm{CO}_{2}-\mathrm{C}$ efflux, and a fluctuating trend of $M_{\mathrm{S}}$ at $15 \mathrm{~cm}$ depth among the four surveyed years of 1999-2002 in a cool-temperate deciduous broad-leaved forest in Japan. Zhang et al. [31] found that the seasonal variation of $R_{s}$ was not completely consistent with the daily mean $T_{\mathrm{s}}$ of the upper $10 \mathrm{~cm}$ and that variations in $R_{s}$ followed GPP during most of the growing seasons in a wheat and maize rotation cropland in the North China Plain. The present study site was a sub-alpine meadow; 
accordingly, the amount of biomass was very small. Moreover, obvious vegetation degradation due to anthropogenic activities has occurred in the region in recent years. Therefore, biomass had a relatively smaller effect on $R_{S}$ in the study site, with the temporal variation of $R_{S}$ being not completely consistent with that of NDVI. The correlation analysis of all measured data (analysis not shown) revealed that the correlation between $R_{S}$ and $T_{\mathrm{s}}$ became lower as soil depth increased $\left(\mathrm{T}_{5}>\mathrm{T}_{10}>\mathrm{T}_{15}\right)$, indicating that the soil respiration rate was more influenced by the soil temperature close to the surface. Since there was no forest cover in the study site, the soil temperature was completely controlled by changes in solar radiation. A lagging phenomenon in which the soil temperature at greater depth showed obvious time hysteresis when compared with the soil temperature near the surface was observed by Huang et al. [23]. The LST tn (nighttime LST from the Terra satellite) captured the seasonal variation of $R_{s}$ best among all the MODIS eight-day LST products in the study site during the nine-year period, which was consistent with the results of other studies. Huang et al. [22] selected the nighttime LST observed by the Terra satellite to estimate $R_{\mathrm{s}}$ at 2 contrasting forest sites, while Huang et al. [23] chose the average LST of daytime and nighttime data from MOD11A2 as a driver of the $R_{\mathrm{S}}$ fitting model of a deciduous broadleaf forest in the midwestern United States. Wu et al. [5] reported that the nighttime LST from the Terra satellite was better correlated with the soil respiration than the daytime LST at a Canadian boreal black spruce stand and indicated that the nighttime LST could be a better estimate of the baseline temperature that regulated plant phenology. These results confirmed that the nighttime land surface temperature data from the MODIS eight-day spatial products captured $R_{\mathrm{S}}$ variation reliably. Mo et al. [30] demonstrated that the $R_{\mathrm{S}}$ of $0{ }^{\circ} \mathrm{C}$ soil temperature at $-1 \mathrm{~cm}$ was higher during autumn than spring because the active soil layer remained large as the deeper soil layers warmed up in the summer. Widen [32] also found that the $R_{s}$ of $0{ }^{\circ} \mathrm{C}$ soil temperature was higher during the highest fine-root production period from July to September. Because of the higher altitude of the study site, measurements could not be operated because of the snow cover and cold temperature from December to March. The spring in north China is short, and the air temperature rises rapidly in May. As a result, the $R_{S}$ in April was lower, while it obviously increased in May and June. In October, the temperature dropped sharply, resulting in the $R_{S}$ being significantly lower than in September. The soil moisture affected root growth, soil microbial activity, and soil metabolic activity, and therefore influenced $R_{s}$. Seasonal variations of $M_{\mathrm{s}}$ at the study site were mainly affected by precipitation. Unlike the obvious seasonal variations in $T_{\mathrm{s}}, M_{\mathrm{s}}$ seasonal variations throughout the measuring period fluctuated between high and low levels. After the precipitation, $M_{\mathrm{s}}$ increased rapidly, but then decreased until the next occurrence of precipitation because of water infiltration, soil evaporation, and plant transpiration. When compared to the relationship between $R_{S}$ and temperature, that of $R_{S}$ and $M_{\mathrm{S}}$ was relatively complex and uncertain because the response of $R_{S}$ to $M_{\mathrm{S}}$ differed during different stages [6]. Under dry soil conditions, the soil biochemistry metabolic activity became frequent as the soil water content improved. When $M_{\mathrm{s}}$ reached $50 \%-80 \%$ of the soil saturated water content, the maximum soil microbial metabolic activity was reached and the $R_{S}$ rate achieved the largest value. As $M_{\mathrm{S}}$ continued to increase, the lack of oxygen prevented aerobic respiration. Therefore, in a certain range of $M_{\mathrm{s}}$, the relationship between the $R_{S}$ rate and $M_{\mathrm{S}}$ was positively correlated, and when $M_{\mathrm{S}}$ goes over a certain range, with the increase of $M_{\mathrm{s}}, R_{s}$ decreased. Precipitation and drought could affect the relationship between $R_{s}$ and $M_{\mathrm{S}}$, with rainfall increasing $R_{\mathrm{S}}$ under drought conditions and reducing it under humid conditions. The $M_{\mathrm{S}}$ in the study site was in the range of $35 \%-55 \%$; therefore, there was virtually no stress of $M_{\mathrm{S}}$ on $R_{S}$. The changes in $M_{\mathrm{S}}$ in such a narrow range did not have a significant effect on $R_{s}$ rate during the measuring years. However, in July of $2009, R_{S}$ was significantly lower than in the same period of other years. Specifically, the value of $T_{\mathrm{s}}, M_{\mathrm{s}}$, and $R_{\mathrm{S}}$ during this period was $17.45^{\circ} \mathrm{C}, 15.78 \%$, and $4.45 \mu \mathrm{mol}$ $\mathrm{CO}_{2} \mathrm{~m}^{-2} \mathrm{~s}^{-1}$, respectively, while in the same period of other measuring years, $T_{\mathrm{S}}$ was around $18^{\circ} \mathrm{C}$, $M_{\mathrm{S}}$ was around $45 \%$, and $R_{\mathrm{S}}$ was about $7 \mu \mathrm{mol} \mathrm{CO} \mathrm{Cm}^{-2} \mathrm{~s}^{-1}$. It can be seen that $T_{\mathrm{s}}$ value was close to each other, while the difference between $M_{\mathrm{s}}$ in July of 2009 and during other years was about $30 \%$, indicating that $R_{\mathrm{S}}$ was inhibited by water stress in July of 2009 . 


\subsection{Factors Affecting the Seasonal Variations of $R_{S}$}

The spatial scales of MODIS data were widely apart, i.e., $500 \mathrm{~m}$ for vegetation indices and $1000 \mathrm{~m}$ for LST, respectively. As the average spatially-distributed observed $R_{\mathrm{S}}$ data represented the mean value of the study site determined by analysis of spatial heterogeneity $[25,26]$, the MODIS products (i.e., LST and NDVI) can be considered to be consistent with the in situ measured data (i.e., $R_{\mathrm{S}}, T_{\mathrm{s}}$, and $M_{\mathrm{S}}$ ) in spatial matching. Moreover, some previous studies have verified the spatial matching of MODIS spatial products and the observation of eddy flux towers [23]. The seasonal variations in $R_{\mathrm{s}}$ may be related to temporal changes in temperature, soil moisture, and other soil physicochemical factors (i.e., SOC, N, pH, etc.), as well as changes in the phenology of biotic factors (i.e., plant photosynthesis and its development phase, fine root production, microbial activity, and below-ground C allocation) $[14,19,30,31,33]$. Soil physical and chemical factors were basically constant on temporal scale in the study site. We selected the most influential environmental factors to model seasonal variations in $R_{\mathrm{s}}$. The capacity of the exponential model to explain the same independent environmental variables was significantly higher than that of the linear model. Based on the $R^{2}$, RMSE, and AIC, a statistically significant difference was not detected among well fitted exponential-type functions considering $T_{\mathrm{S}}$ alone, $T_{\mathrm{S}}$ and $M_{\mathrm{S}}$, or $T_{\mathrm{S}}$, $M_{\mathrm{S}}$ and NDVI together. The soil water supply was generally sufficient in the study site; therefore, adding it into the fitting model did not significantly improve the model explanatory capacity. Moreover, the addition of NDVI did not greatly improve the explanation capacity, possibly because of the lower above-ground biomass in the study site. The exponential function driven by $T_{\mathrm{s}}$ was selected as the best fitted model to estimate the seasonal variations of $R_{\mathrm{S}}$ in the study site as it needed only one unknown independent variable. This finding indicated that the contribution of the soil moisture and vegetation index to $R_{\mathrm{S}}$ was relatively small and temperature exerted the greatest control on $R_{\mathrm{S}}$ in the study site. In another alpine meadow on the Tibetan Plateau, Hu et al. [34] found that soil temperature and above-ground biomass rather than soil moisture mainly affected the ecosystem respiration. Findings of the present study were in agreement with those of previous studies that showed $R_{\mathrm{s}}$ was most sensitive to the soil temperature among all related environmental factors on a temporal scale $[8,13,35]$, on account of the principle that soil temperature acted as a dominant climatic factor on $R_{\mathrm{s}}$ alongside impact substrate and physiological activities, which ultimately affected $R_{\mathrm{s}}$. Therefore, temperature could be a reliable predictor for the seasonal variation in $R_{\mathrm{s}}$. However, several studies have shown that $R_{\mathrm{S}}$ was most closely related to the soil moisture under dry conditions [36]. It depends on which factor is the limiting factor in any given ecosystem. In the present study, $M_{\mathrm{s}}$ was sufficient, so its impact on $R_{\mathrm{S}}$ was smaller. Therefore, the decisive driver of $R_{\mathrm{S}}$ was not the same under different environmental conditions. The unexplained $R_{\mathrm{S}}$ seasonal variation based on our selected model may have been due to the microbial properties and soil physical and chemical properties related to $R_{\mathrm{S}}$, since the addition of $M_{\mathrm{S}}$ and NDVI did not significantly improve the explanatory power. The model driven only by temperature may have masked several biotic processes (e.g., plant photosynthesis and microbial activities), abiotic processes (e.g., water supply) and their combined effects [22,37], but it also avoided the multi-collinearity problems among the independent variables and the increasing uncertainty of model based predictions caused by increases in independent variables [22]. For example, soil temperature influenced root respiration and microbial activities [38], soil moisture influenced the physiological processes of roots and microorganisms [39], etc. The $R^{2}$ value of the exponential model driven by LST was $0.762^{* * *}$, which was slightly lower than the $R^{2}$ value of the $T_{\mathrm{S}}$ exponential model $\left(0.842^{* * *}\right)$, indicating that LST also provided useful information for fitting seasonal variations in $R_{\mathrm{s}}$. The $t$-test analysis of modeling performing indicators (i.e., $R^{2}$, RMSE, and AIC) in each year of the two best fitted one-variable exponential model showed that there was no significant difference between the $T_{\mathrm{s}}$ exponential model and the LST exponential model. These findings confirmed the potential role of remote sensing data to estimate the seasonal variations in $R_{\mathrm{s}}$ on a regional scale $[5,14,22,23,37]$. Moreover, these results validated the applicability of spatial data products in $R_{\mathrm{s}}$ temporal dynamic modeling and provided data support for estimating $R_{\mathrm{s}}$ using spatial data products on a large scale. 


\subsection{Temperature Sensitivity of $R_{S}$}

Previous studies have mostly focused on the relationship between $R_{\mathrm{s}}$ and its related environmental factors, and $\mathrm{Q}_{10}$ has been studied as an index to evaluate the temperature sensitivity of $R_{\mathrm{s}}$. Moreover, some researchers have studied the environmental factors affecting $Q_{10}$ [2]. In the study site, the seasonal variations in the soil respiration sensitivity index, $\mathrm{Q}_{10}$, showed a curve opposite to that of $R_{\mathrm{S}}$ and $T_{\mathrm{S}}$ with hysteresis. Despite considering the fact that $\mathrm{Q}_{10}$ was controlled by the soil temperature, soil moisture [40], organic matter decomposition [41], soil physical and chemical properties and biotic factors such as vegetation cover and fine root mass [19], also varied depending on the location [13], the differences among monthly $\mathrm{Q}_{10}$ values may mainly be controlled by the combination of soil moisture and soil temperature because of the relatively constant soil physical and chemical properties in study site.

The $\mathrm{Q}_{10}$ values for different temperature intervals indicated a negative response of $\mathrm{Q}_{10}$ to $R_{\mathrm{s}}$ and $T_{\mathrm{S}}$ in accordance with previously published studies [1,2,40,42]. The physical and bio-chemical process consisting of $R_{\mathrm{S}}$ was constrained by lower temperatures; thus, an increase of temperature could significantly improve the soil respiration rate, resulting in a higher $\mathrm{Q}_{10}$ at lower temperatures. However, under higher temperatures that had met the need of $R_{\mathrm{s}}$, further increases in temperature did not improve $R_{\mathrm{s}}$, resulting in a lower $\mathrm{Q}_{10}$ [43]. The $\mathrm{Q}_{10}$ acclimated to the soil temperature because of the sufficient soil moisture in the study site. The annual $\mathrm{Q}_{10}$ values ranged from 1.84 to 3.78 with a mean value of $2.90 \pm 0.59$, which were slightly higher than the global mean of 2.4 and range of 1.3 to 3.3 [44]. The temperature in the study site was much lower because of the high altitude, and the actual $\mathrm{Q}_{10}$ value may have been slightly higher than the calculated mean value because of the missing data for the coldest days when the measurements could not be taken. Within the soil temperature range of $-0.1^{\circ} \mathrm{C}$ to $20.68^{\circ} \mathrm{C}$ of the nine-year measured data, the $\mathrm{Q}_{10}$ value based on all measured data was approximately 3.08, which was almost equal to the mean $Q_{10}$ value $(2.90 \pm 0.59)$ of the annual $Q_{10}$. It should be noted that the $Q_{10}$ value was quite low under water stress in 2009, indicating that the response of $R_{\mathrm{S}}$ to temperature was obviously inhibited by water stress when there was a low water supply. The $\mathrm{R}_{10}$ value $\left(3.01 \pm 0.27 \mu \mathrm{mol} \mathrm{CO} \mathrm{CO}^{-2} \mathrm{~s}^{-1}\right)$ in the study site was comparable to that of other studies, such as 1.27-2.90 for 11 sites with four types of land cover in a mountain area investigated by Li et al. [19] and 2.30-3.60 in a temperate deciduous forest studied by Vincent et al. [45].

\section{Conclusions}

The findings present that soil temperature near the surface soil exerts dominant control on soil respiration rate at a seasonal scale due to the lower above-ground biomass and sufficient soil moisture supply. The seasonal variations in $R_{\mathrm{S}}$ can be effectively estimated based on the proposed $T_{\mathrm{s}}$-exponential model in the study area. Also, the high explanation capacity of the LST-exponential model highlights a promising prospect of applying the remote sensing products to the seasonal estimating model of $R_{s}$ during further exploration. The $\mathrm{Q}_{10}$ seasonal variation presents a concave type distribution, with its value significantly controlled by temperature under lower temperature conditions. The results presented herein demonstrate the determining role of temperature in $R_{\mathrm{s}}$ seasonal variations in a sub-alpine meadow zone and quantitively verify the applicability of spatial data products for estimating $R_{\mathrm{S}}$ temporal variations.

Author Contributions: Conceptualization, Y.L., Y.C. and J.Y.; data curation, Y.L., J.Y. and H.L.; formal analysis, Y.L.; investigation, Y.L. and H.L.; supervision, H.L.; writing-original draft, Y.L.; writing-review and editing, Y.C.; funding acquisition, Y.C. and J.Y.

Funding: This research was funded by the National Key Research Program of China (Grant No. 2016YFC0502209), the National Natural Science Foundation of China (Grant No. 51522901, Grant No. 41201374) and the Fundamental Research Funds for the Central Universities.

Acknowledgments: We would like to express our gratitude to the anonymous reviewers and the editors for providing us the valuable comments and suggestions in improving our manuscript.

Conflicts of Interest: The authors declare no conflict of interest. 


\section{References}

1. Han, M.G.; Jin, G.Z. Seasonal variations of $Q(10)$ soil respiration and its components in the temperate forest ecosystems, northeastern China. Eur. J. Soil Biol. 2018, 85, 36-42. [CrossRef]

2. Zhao, K.J.; Dong, B.Q.; Jia, Z.K.; Ma, L. Effect of climatic factors on the temporal variation of stem respiration in Larix principis-rupprechtii Mayr. Agric. For. Meteorol. 2018, 248, 441-448. [CrossRef]

3. Zhao, Y.L.; Goldberg, S.D.; Xu, J.C.; Harrison, R.D. Spatial and seasonal variation in soil respiration along a slope in a rubber plantation and a natural forest in Xishuangbanna, Southwest China. J Mt. Sci. 2018, 15, 695-707. [CrossRef]

4. Ohashi, M.; Gyokusen, K. Temporal change in spatial variability of soil respiration on a slope of Japanese cedar (Cryptomeria japonica D. Don) forest. Soil Biol. Biochem. 2007, 39, 1130-1138. [CrossRef]

5. Wu, C.Y.; Gaumont-Guay, D.; Black, T.A.; Jassal, R.S.; Xu, S.G.; Chen, J.M.; Gonsamo, A. Soil respiration mapped by exclusively use of MODIS data for forest landscapes of Saskatchewan, Canada. ISPRS J. Photogramm. Remote Sens. 2014, 94, 80-90. [CrossRef]

6. Raich, J.W.; Potter, C.S. Global Patterns of Carbon-Dioxide Emissions from Soils. Glob. Biogeochem. Cycle 1995, 9, 23-36. [CrossRef]

7. Foti, S.; Balogh, J.; Nagy, Z.; Herbst, M.; Pinter, K.; Peli, E.; Koncz, P.; Bartha, S. Soil moisture induced changes on fine-scale spatial pattern of soil respiration in a semi-arid sandy grassland. Geoderma 2014, 213, $245-254$. [CrossRef]

8. Munoz-Rojas, M.; Lewandrowski, W.; Erickson, T.E.; Dixon, K.W.; Merritt, D.J. Soil respiration dynamics in fire affected semi-arid ecosystems: Effects of vegetation type and environmental factors. Sci. Total Environ. 2016, 572, 1385-1394. [CrossRef]

9. Bond-Lamberty, B.; Thomson, A. Temperature-associated increases in the global soil respiration record. Nature 2010, 464, 579. [CrossRef]

10. Zeng, X.H.; Song, Y.G.; Zhang, W.J.; He, S.B. Spatio-temporal Variation of Soil Respiration and Its Driving Factors in Semi-arid Regions of North China. Chin. Geogr. Sci. 2018, 28, 12-24. [CrossRef]

11. Ahmad, W.; Singh, B.; Dijkstra, F.A.; Dalal, R.C.; Geelan-Small, P. Temperature sensitivity and carbon release in an acidic soil amended with lime and mulch. Geoderma 2014, 214, 168-176. [CrossRef]

12. Ahmad, W.; Singh, B.; Dijkstra, F.A.; Dalal, R.C. Inorganic and organic carbon dynamics in a limed acid soil are mediated by plants. Soil Biol. Biochem. 2013, 57, 549-555. [CrossRef]

13. Lloyd, J.; Taylor, J.A. On the temperature-dependence of soil respiration. Funct. Ecol. 1994, 8, 315-323. [CrossRef]

14. Sanchez, M.L.; Ozores, M.I.; Lopez, M.J.; Colle, R.; De Torre, B.; Garcia, M.A.; Perez, I. Soil CO 2 fluxes beneath barley on the central Spanish plateau. Agric. For. Meteorol. 2003, 118, 85-95. [CrossRef]

15. Borken, W.; Xu, Y.J.; Brumme, R.; Lamersdorf, N. A climate change scenario for carbon dioxide and dissolved organic carbon fluxes from a temperate forest soil: Drought and rewetting effects. Soil Sci. Soc. Am. J. 1999, 63, 1848-1855. [CrossRef]

16. Birch, H.F. The effect of soil drying on humus decomposition and nitrogen availability. Plant Soil 1958, 10, 9-31. [CrossRef]

17. Ahmad, W.; Singh, B.; Dalal, R.C.; Dijkstra, F.A. Carbon dynamics from carbonate dissolution in Australian agricultural soils. Soil Res. 2015, 53, 144-153. [CrossRef]

18. Samuelson, L.; Mathew, R.; Stokes, T.; Feng, Y.C.; Aubrey, D.; Coleman, M. Soil and microbial respiration in a loblolly pine plantation in response to seven years of irrigation and fertilization. For. Ecol. Manag. 2009, 258, 2431-2438. [CrossRef]

19. Li, H.J.; Yan, J.X.; Yue, X.F.; Wang, M.B. Significance of soil temperature and moisture for soil respiration in a Chinese mountain area. Agric. For. Meteorol. 2008, 148, 490-503. [CrossRef]

20. Zhang, Q.; Katul, G.G.; Oren, R.; Daly, E.; Manzoni, S.; Yang, D.W. The hysteresis response of soil $\mathrm{CO}_{2}$ concentration and soil respiration to soil temperature. J. Geophys. Res. Biogeosci. 2015, 120, 1605-1618. [CrossRef]

21. Huang, N.; Niu, Z. Estimating soil respiration using spectral vegetation indices and abiotic factors in irrigated and rainfed agroecosystems. Plant Soil 2013, 367, 535-550. [CrossRef]

22. Huang, N.; Gu, L.H.; Black, T.A.; Wang, L.; Niu, Z. Remote sensing-based estimation of annual soil respiration at two contrasting forest sites. J. Geophys. Res. Biogeosci. 2015, 120, 2306-2325. [CrossRef] 
23. Huang, N.; Gu, L.H.; Niu, Z. Estimating soil respiration using spatial data products: A case study in a deciduous broadleaf forest in the Midwest USA. J. Geophys. Res. Atmos. 2014, 119, 6393-6408. [CrossRef]

24. Suqing, L.I.; Jintun, Z. Ecological analysis of subalpine meadow in Yunding Mountain, Shanxi. Geogr. Res. 2007, 26, 83-90.

25. Yan, J.-X.; Li, J.-J.; Li, H.-J.; Zhang, Y.-H. Studies on spatial heterogeneity of soil respiration in a subalpine meadow. Huanjing Kexue 2013, 34, 3992-3999. [PubMed]

26. Li, H.-J.; Gao, Y.-F.; Yan, J.-X.; Li, J.-J. Spatial heterogeneity of soil respiration in a subalpine meadow at different sampling scales. Huanjing Kexue 2014, 35, 4313-4320. [PubMed]

27. Wan, Z.M. New refinements and validation of the MODIS Land-Surface Temperature/Emissivity products. Remote Sens. Environ. 2008, 112, 59-74. [CrossRef]

28. Huang, N.; He, J.S.; Niu, Z. Estimating the spatial pattern of soil respiration in Tibetan alpine grasslands using Landsat TM images and MODIS data. Ecol. Indic. 2013, 26, 117-125. [CrossRef]

29. Rouse, J.W.; Haas, R.H.; Schell, J.A.; Deering, D.W.; Harlan, J.C. Monitoring the Vernal Advancements and Retrogradation of Natural Vegetation; Texas A \& M University, Remote Sensing Center: Greenbelt, MD, USA, 1974.

30. Mo, W.; Lee, M.S.; Uchida, M.; Inatomi, M.; Saigusa, N.; Mariko, S.; Koizumi, H. Seasonal and annual variations in soil respiration in a cool-temperate deciduous broad-leaved forest in Japan. Agric. For. Meteorol. 2005, 134, 81-94. [CrossRef]

31. Zhang, Q.; Lei, H.M.; Yang, D.W. Seasonal variations in soil respiration, heterotrophic respiration and autotrophic respiration of a wheat and maize rotation cropland in the North China Plain. Agric. For. Meteorol. 2013, 180, 34-43. [CrossRef]

32. Widen, B. Seasonal variation in forest-floor CO2 exchange in a Swedish coniferous forest. Agric. For. Meteorol. 2002, 111, 283-297. [CrossRef]

33. Kato, T.; Tang, Y.H.; Gu, S.; Cui, X.Y.; Hirota, M.; Du, M.Y.; Li, Y.N.; Zhao, Z.Q.; Oikawa, T. Carbon dioxide exchange between the atmosphere and an alpine meadow ecosystem on the Qinghai-Tibetan Plateau, China. Agric. For. Meteorol. 2004, 124, 121-134. [CrossRef]

34. Hu, Y.G.; Jiang, L.L.; Wang, S.P.; Zhang, Z.H.; Luo, C.Y.; Bao, X.Y.; Niu, H.S.; Xu, G.P.; Duan, J.C.; Zhu, X.X.; et al. The temperature sensitivity of ecosystem respiration to climate change in an alpine meadow on the Tibet plateau: A reciprocal translocation experiment. Agric. For. Meteorol. 2016, 216, 93-104. [CrossRef]

35. Jenkins, M.E.; Adams, M.A. Respiratory quotients and Q(10) of soil respiration in sub-alpine Australia reflect influences of vegetation types. Soil Biol. Biochem. 2011, 43, 1266-1274. [CrossRef]

36. Moyano, F.E.; Manzoni, S.; Chenu, C. Responses of soil heterotrophic respiration to moisture availability: An exploration of processes and models. Soil Biol. Biochem. 2013, 59, 72-85. [CrossRef]

37. Huang, N.; Niu, Z.; Zhan, Y.L.; Xu, S.G.; Tappert, M.C.; Wu, C.Y.; Huang, W.J.; Gao, S.; Hou, X.H.; Cai, D.W. Relationships between soil respiration and photosynthesis-related spectral vegetation indices in two cropland ecosystems. Agric. For. Meteorol. 2012, 160, 80-89. [CrossRef]

38. Wan, S.; Norby, R.J.; Ledford, J.; Weltzin, J.F. Responses of soil respiration to elevated CO2, air warming, and changing soil water availability in a model old-field grassland. Glob. Chang. Biol. 2007, 13, 2411-2424. [CrossRef]

39. Huang, G.; Li, Y.; Su, Y.G. Effects of increasing precipitation on soil microbial community composition and soil respiration in a temperate desert, Northwestern China. Soil Biol. Biochem. 2015, 83, 52-56. [CrossRef]

40. Jiang, J.S.; Guo, S.L.; Zhang, Y.J.; Liu, Q.F.; Wang, R.; Wang, Z.Q.; Li, N.N.; Li, R.J. Changes in temperature sensitivity of soil respiration in the phases of a three-year crop rotation system. Soil Tillage Res. 2015, 150, 139-146. [CrossRef]

41. Davidson, E.A.; Janssens, I.A. Temperature sensitivity of soil carbon decomposition and feedbacks to climate change. Nature 2006, 440, 165-173. [CrossRef]

42. Janssens, I.A.; Pilegaard, K. Large seasonal changes in $\mathrm{Q}(10)$ of soil respiration in a beech forest. Glob. Chang. Biol. 2003, 9, 911-918. [CrossRef]

43. Andrews, J.A.; Matamala, R.; Westover, K.M.; Schlesinger, W.H. Temperature effects on the diversity of soil heterotrophs and the delta C-13 of soil-respired CO2. Soil Biol. Biochem. 2000, 32, 699-706. [CrossRef] 
44. Raich, J.W.; Schlesinger, W.H. The global carbon-dioxide flux in soil respiration and its relationship to vegetation and climate. Tellus Ser. B Chem. Phys. Meteorol. 1992, 44, 81-99. [CrossRef]

45. Vincent, G.; Shahriari, A.R.; Lucot, E.; Badot, P.M.; Epron, D. Spatial and seasonal variations in soil respiration in a temperate deciduous forest with fluctuating water table. Soil Biol. Biochem. 2006, 38, 2527-2535. [CrossRef] 